\title{
Multi-Drug Induced Palmar and Plantar Lichen Planus: First Description in the Medical Literature!
}

\author{
Georgi Tchernev ${ }^{1}{ }^{2 *}$, Uwe Wollina ${ }^{3}$ and Ivanka Temelkova ${ }^{1}{ }^{2}$ \\ ${ }^{1}$ Department of Dermatology, Venereology and Dermatologic surgery, Medical Institute of Ministry of Interior (MVR); Sofia, Bulgaria \\ ${ }^{2}$ Onkoderma- Clinic for Dermatology, Venereology and Dermatologic Surgery; Sofia, Bulgaria \\ ${ }^{3}$ Department of Dermatology and Allergology, Stadtisches Klinikum Dresden, Germany
}

Received: July 17, 2019; Accepted: July 23, 2019; Published: July 26, 2019

*Corresponding author: Prof. Dr. Georgi Tchernev, Department of Dermatology, Venereology and Dermatologic Surgery, Medical Institute of Ministry of Interior (MVR), General Skobelev 79, 1606 Sofia, Bulgaria, E-mail: georgi_tchernev@yahoo.de

Key words: Drug Induced Lichenoid Reaction; Lichen Planus; ASS; Rosuvastatin; Ramipiril; Metoprolol

\section{Introduction}

We report a case of a 43-year-old male patient who developed palmoplantar violaceous papules, subsequently diagnosed as drug-induced lichen planus (LP) based on the histopathological findings and clinical correlation (figures. 1a, 1b).
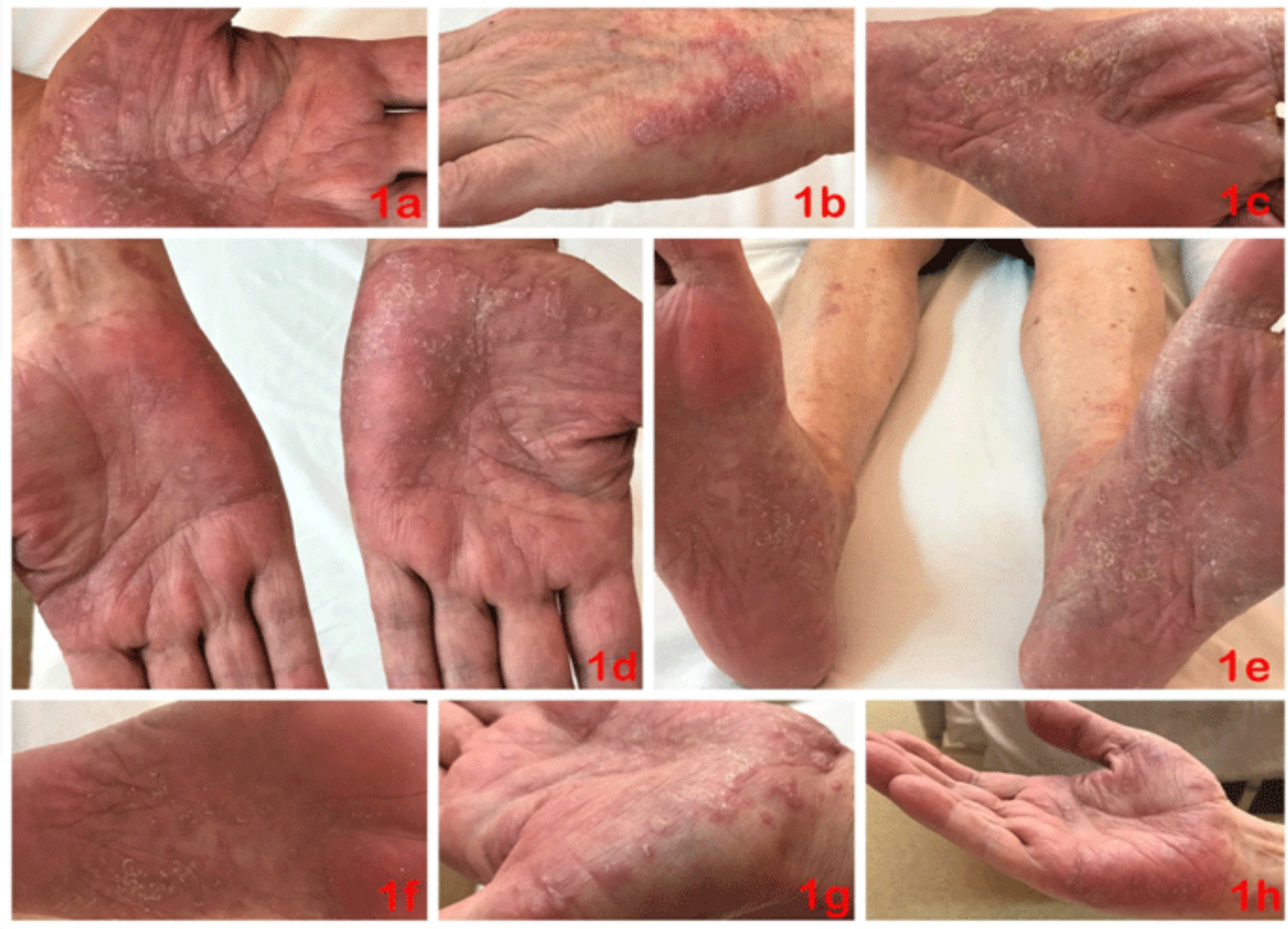

Figs. Designations:

1a. Lesions of the palmar aspect of the upper limbs characterized by shiny erythematous to purple-colored flat-topped papules. 1b. Lesions of the dorsal aspect of the upper limbs characterized by shiny erythematous to purple-colored flat-topped papules.

1c. Lesions of the plantar surface of the feet with diffuse violaceous erythema and erythematous to purple-colored flat-topped papules.

1d. Lesions of the palmar part of the upper limbs characterized by shiny erythematous to purple-colored flat-topped papules. 
The lesions had started three months earlier when the patient noticed a rash characterized by redness and swelling of the skin on the palms and soles (figures. 1c, 1d), accompanied by severe itching.

Previous medical history was relevant for myocardial infarction (2014). His current diseases were glaucoma, arterial hypertension and hypercholesterolemia. Systemic medication at the time of hospitalization included rosuvastatin $20 \mathrm{mg}(0-0$ 1), metoprolol succinate $50 \mathrm{mg}$ (1/2-0-0), ramipril $10 \mathrm{mg}(1 / 2$ $0-1 / 2)$ and acetylsalicylic acid $75 \mathrm{mg}(0-0-1)$. One year later he developed cutaneous skin lesions, identified later as palmoplantar LP. At the time of hospitalization there were no evidence of bacterial or viral infections (Hepatitis B, Hepatitis C, HIV).

In consultation with a cardiologist it was decided to stop rosuvastatin, ramipril, metoprolol succinate and acetylsalicylic acid, and in replacement the patient started lercanidipine 10 mg bid, clopidogrel $75 \mathrm{mg}$ id and ivabradine. After stopping the suspected drugs, treatment with acitretin $40 \mathrm{mg} /$ daily was initiated. Additionally, the patient received desloratadine $5 \mathrm{mg}$ id and topical therapy with methylprednisolone aceponate cream twice daily, with durable response after one month.

Recent literature suggests that drugs such as nebivolol and acetylsalicylic acid are associated with the induction of LP [1]. Current data also raise the possibility that drugs such as pembrolizumab, interferon- $\alpha$, fenofibrate, telmisartan and brimonidine may also play a significant role in the induction of LP [2-6].

Lichen planus is a relatively common skin disorder of unknown etiology, but many studies in the literature suggest that one of the possible causes is systemic administration of different drugs. Sufficient evidence exists to support the thesis that betablockers, methyldopa, penicillamine, quinidine and quinine may play a pathogenic role and are potential triggers of the disease [7]. Given the available epidemiologic evidence, nonsteroidal antiinflammatory drugs could also be considered as a potential causative agents $[1,11]$.
The information we have gathered has lead us to the final conclusion that the medications that the patient was taking (rosuvastatin, metoprolol, ramipril and acetylsalicylic acid) may have triggered a multi- drug-induced palmoplantar LP [8 -11].

All information about our patient and data from world literature suggest that this is the first case of a patient developing a multi drug-related palmoplantar variant of LP.

\section{References}

1. Mahboob A, Haroon TS. Drugs causing fixed eruptions: a study of 450 cases. Int J Dermatol. 1998;37(11):833-838.

2. Denny J, Chong H, Akhras V. Lichen planus in a patient treated with pembrolizumab for metastatic malignant melanoma. Clin Exp Dermatol. 2018;43(3):354-356. doi: 10.1111/ced.13315

3. Bush AE, Hymes SR, Silapunt S. Lichenoid Dermatitis From Interferon alpha-2a in a Patient With Metastatic Renal Cell Carcinoma and Seronegative HCV. J Drugs Dermatol. 2017;16(7):714-716.

4. Mohammed F, Wally LL, Karaban JE, Reddy VB, Lertratanakul Y. Fenofibrate-Induced Lichenoid Drug Eruption: A Rare Culprit. Case Rep Dermatol. 2017;9(3):236-242. doi: 10.1159/000484471

5. Ventura-Abreu N, Fernández-Aceñero MJ, Narváez-Palazón C, RomoLópez A. Brimonidine-induced unilateral ocular lichen planus: a case report. Arq Bras Oftalmol. 2019;82(3):236-238. doi: 10.5935/00042749.20190047

6. Chan WP, Mackey VT, Sun DK. Telmisartan-induced lichen planus eruption manifested on vitiliginous skin. Cutis. 2017;99(1):E16-E19.

7. Thompson DF, Skaehill PA. Drug-induced lichen planus. Pharmacotherapy. 1994;14(5):561-571.

8. Rosmaninho A, Sanches M, Oliveira A, Alves R, Selores M. Lichen planus pemphigoides induced by a weight reduction drug. Cutan Ocul Toxicol. 2011;30(4):306-308. doi: 10.3109/15569527.2011.566234

9. Vesza Z, Pires C, da Silva PM. Statin-related Lichenoid Dermatosis: An Uncommon Adverse Reaction to a Common Treatment. Eur J Case Rep Intern Med. 2018;5(5): 000844. doi: 10.12890/2018_000844

10. Fessa C, Lim P, Kossard S, Richards S, Peñas PF. Lichen planus-like drugeruptions due to $\beta$-blockers: a case report and literature review. Am J Clin Dermatol. 2012;13(6):417-21. doi: 10.2165/11634590000000000-00000

11. Ruiz Villaverde R, Blasco Melguizo J, Mendoza Guil F, Martín Sánchez MC, Naranjo Sintes R. Generalized lichen planus-like eruption due to acetylsalicylic acid . J Eur Acad Dermatol Venereol. 2003;17(4):470472. 